\title{
Co-occurrence of depression, anxiety disorders, and obesity. Comparison of overweight and obese patients with patients with correct body weight in terms of expansion of depression-anxiety symptoms
}

\author{
Małgorzata Obara-Gołębiowska \\ Department of Psychology of Development and Education, University of Warmia and Mazury, Olsztyn, Poland
}

\begin{abstract}
Introduction: Depression, anxiety disorders, and obesity are commonly co-occurring disorders. Due to the scarcity of research on the expansion of depression-anxiety disorders in the group of people with body mass index $(\mathrm{BMI}) \geq 25$, the objective of this paper is to analyse the level of depression and anxiety in a group of obese patients of the Obesity Treatment Ward, and to compare the group to patients with correct body weight.

Material and methods: The research covered two equal research groups. The first research group comprised 54 obese female patients of the Obesity Treatment Ward. The second research group comprised 54 female patients with correct body weight from the Non-Public Health Centre in Butryny (Warminsko-Mazurskie Province). The applied research tool was the Hospital Anxiety and Depression Scale HADS.

Results: The statistical analysis of results of the present study showed a significantly higher level of depression: $t(52)=4.81, p<0.05$, and anxiety: $t(52)=3.64, p<0.05$, in the HADS scale among overweight or obese persons in comparison to those with correct body weight.

Conclusions: The results of the study showed significantly higher intensity of depression-anxiety disorders among obese persons in comparison to those with correct body weight. Obese persons should receive standard psychological support during weight loss treatments due to the level of anxiety and/or depression.
\end{abstract}

Key words: obesity, depression, anxiety.

\section{Introduction}

Depression, anxiety disorders, and obesity are commonly co-occurring disorders. This may be determined by their common biological background [1]. Moreover, depression and obesity have been determined to potentially represent the same pathological process. Particularly, atypical forms of depression are related to an increase in appetite, regulation of emotions by means of food, reduction of physical activity, and therefore an increase in body weight [2]. Moreover, psychological consequences resulting from social stigmatisation of obesity cause the occurrence or intensification of pre-existing depression-anxiety problems $[3,4]$. Results of long-term research also emphasise the strong mutual correlation between obesity and depression. It shows that depression increases the probability of the development of obesity. An opposite dependency also exists, where being obese causes depression. Moreover, efficient reduction of weight turns out to be a factor in decreasing the level of depression. Being depressive makes it difficult to change one's eating habits, and therefore - to lose excessive weight [5].

Due to the scarcity of research on the expansion of depression-anxiety disorders in the group of people with $\mathrm{BMI} \geq 25$, the objective of this paper is to analyse the level of depression and anxiety in a group of obese patients of the Obesity Treatment Ward, and to compare the group to patients with correct body weight. 


\section{Material and methods}

The research covered two equal research groups. All participants gave verbal consent to participate, and the study was approved by the Bioethics Committee of University of Warmia and Mazury, Olsztyn, Poland. The first research group comprised 54 obese female patients of the Obesity Treatment Ward. The mean age of the patients amounted to 48.1 (range: 23-63) years of age. The mean body mass index amounted to 36.4 (range: 25-51). The second research group comprised 54 female patients with correct body weight from the Non-Public Health Centre in Butryny (Warminsko-Mazurskie Province). The mean age of the patients amounted to 46.7 (range: 24-65) years of age. The mean body mass index (BMI) amounted to 23.8 (range: $22.3-24.8$ ). The applied research tool was the Hospital Anxiety and Depression Scale HADS [6]. The questionnaire is applied to analyse the level of anxiety and depression in hospitalised patients and outpatients. This research employed the HADS scale in the Polish adaptation by de Walden-Gałuszko and Majkowicz [7].

\section{Results}

Results of the study were verified in the statistical program SPSS 22 on the basis of Student $t$-test. Based on the conducted research, it was observed that in the group of obese patients (group I), increased anxiety level occurred in $30 \%$ of the patients, including $10 \%$ showing anxiety at a pathological level. An increased level of depression was recorded among 32\% of patients, including 15\% with pathologically intensified depression symptoms. For comparison, an increased anxiety level occurred in $12 \%$ of patients with correct body weight (group II), and increased level of depression - in $16 \%$. No cases of pathological anxiety or depression were recorded in group II. The statistical analysis of results of the present study showed a significantly higher level of depression and anxiety in the HADS scale among overweight or obese persons in comparison to those with correct body weight:

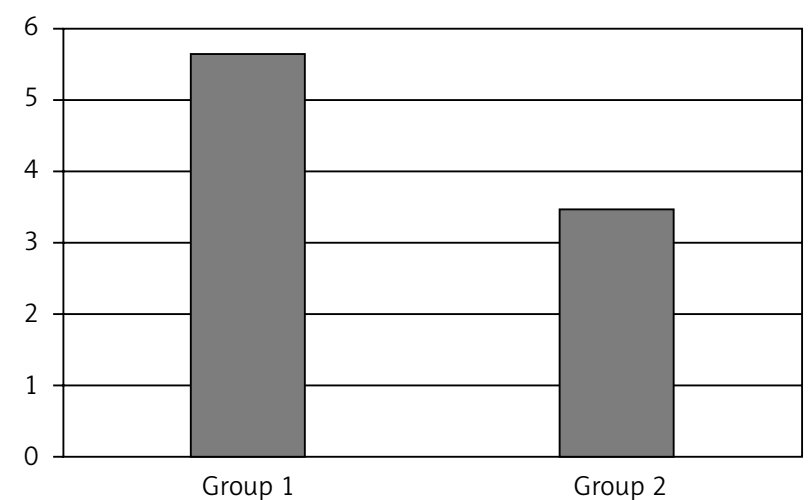

Figure 1. Level of anxiety in group 1 and group 2
- anxiety level: $\mathrm{M}($ group 1$)=5.66 ; \mathrm{SD}=3.37, \mathrm{M}$ (group 2) $=3.48 ; \mathrm{SD}=2.57 ; t(52)=3.64, p<0.05$ (Figure 1),

- depression level (HADS): $\mathrm{M}$ (group 1) = 6.38; $\mathrm{SD}=3.12$, $\mathrm{M}($ group 2$)=3.56 ; \mathrm{SD}=2.74 ; t(52)=4.81, p<0.05$ (Figure 2).

\section{Discussion}

The results of the presented study are of great importance for clinical practice in obesity treatment. Similar results were obtained among others in research by Svenningsson et al. [8], where depression and anxiety disorders were diagnosed in $25 \%$ of obese patients. Also in the study of Hung-Yen et al. [9] different types of mood disorders were observed in $27.1 \%$ of patients. The most common disorder was dysthymia, and anxiety disorders were found in $18.2 \%$ of people. The results of both studies, although methodologically different, seem to correspond with each other. The coexistence of obesity with the problems of depression and anxiety has been shown in numerous scientific studies [10-12].

Moreover, results of the presented study showed significantly higher intensity of depression-anxiety disorders among obese persons in comparison to those with correct body weight. The above results are in accordance with the studies of Hung-Yen et al. [9] and Heo et al. [12]. Obese persons should receive standard psychological support during weight-loss treatments due to the frequently increased level of anxiety and/or depression in the group. Moreover, particular attention should be paid to patients in whom the level of anxiety and/or depression is at a pathological level. They may require pharmaceutical intervention. It is probably also a group particularly prone to failures in the scope of change of eating habits. Psychological condition is evidently a factor determining the efficiency and sustainability of the change of lifestyle associated to the goal of body weight reduction [9]. Taking the individual psychosocial context of the patient into consideration in treatment permits the implementation of the objective of, among others, achievement of internal psychological bal-

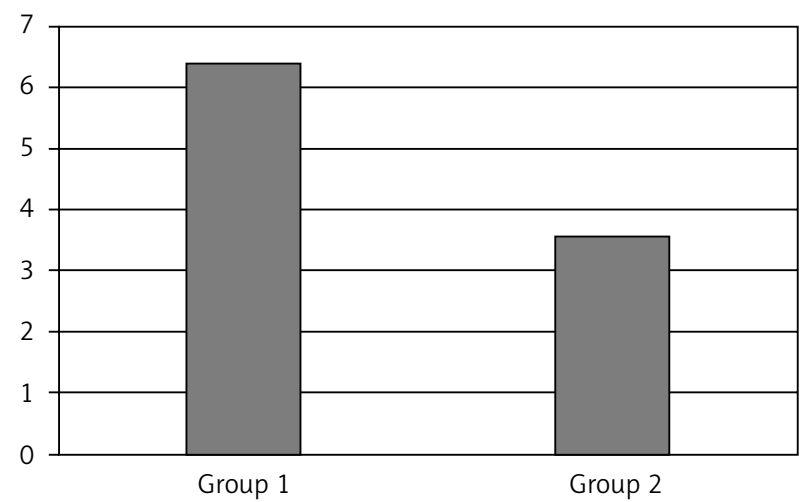

Figure 2. Level of depression in group 1 and group 2 
ance by the patient. Psychological practice in the scope of therapy of overweight persons shows that psychological destabilisation leading to a decrease in the quality of life of an individual frequently results in excessive eating. Unfortunately, such a form of compensation directly results in overweight or obesity, and sometimes also in the appearance of deeper psychopathological disorders [13].

\section{Conclusions}

The results of the study showed significantly higher intensity of depression-anxiety disorders among obese persons in comparison to those with correct body weight.

Obese persons should receive standard psychological support during weight loss treatments due to the level of anxiety and/or depression.

\section{Disclosure}

Author reports no conflict of interest.

\section{References}

1. Bornstein SR, Schuppenies A, Wong ML, et al. Approaching the shared biology of obesity and depression: the stress axis as the locus of gene-environment interactions. Mol Psychiatr 2006; 11: 892-902.

2. Rosmond R. Obesity and depression: same disease, different names? Med Hypotheses 2004; 62: 976-979.

3. Puhl RM, Brownell KD. Psychosocial origins of obesity stigma: toward changing a powerful and pervasive bias. Obesity Review 2003; 4: 213-227.

4. Oyekcin DG, Yildiz D, Şahin EM, Gür S. Depression and Anxiety in Obese Patients. Turkish Journal of Endocrinology and Metabolism 2011; 15: 121-124.

5. Jackson S, Steptoe A, Beeken R, et al. Psychological changes following weight loss in overweight and obese adults: Prospective cohort study. PLoS One 2014; 9: 1-8.

6. Zigmond AS, Snaith RP. The Hospital Anxiety and Depression Scale. Acta Psychiatr Scand 1983; 67: 361-370.

7. Majkowicz M. Practical assessment of palliative care effectiveness - selected research methods. In: de Walden-Gałuszko K, Majkowicz $M$ (eds.). Assessment of palliative care quality in theory and practice. Uniwersytet Medyczny w Gdańsku, Gdańsk 2000; 21-42.

8. Svenningsson I, Björkelund C, Marklund B, et al. Anxiety and depression in obese and normal-weight individuals with diabetes type 2: A gender perspective. Scand J Caring Sci 2012; 2: 349-354.

9. Hung-Yen L, Chih-Kun H, Chi-Ming T, et al. Psychiatric disorders of patients seeking obesity treatment. BMC Psychiatry 2013; 13: 1-8.

10. World Health Organization. Obesity: preventing and managing the global epidemic. Report of a WHO Consultation. World Health Organization, Geneva 2004.

11. Ormel J, Petukhova M, Chatterji S, et al. Disability and treatment of specific mental disorders across the world. Br J Psychiatry 2008; 192: 368-375.

12. Heo M, Pietrobelli A, Fontaine KR, et al. Depressive mood and obesity in US adults: comparison and moderation by sex, age, and race. Int J Obesity 2006; 30: 513-519.

13. Salokangas RK, Ruhrmann S, von Reventlow HG, et al. 0-51 Axis I diagnoses and transition to psychosis in clinical high-risk patients. Eur Psychiat 2012; 27: 1-1. 